\title{
Increase Engaged Student Learning Using Google Docs as a Discussion Platform
}

\begin{abstract}
Online discussion board activities have traditionally been a primary method of providing student-to-student interaction, especially in asynchronous online classes. This study examines the impact of an alternate online discussion tool on student participation in online discussion assignments. Three identical discussion assignments were examined over the course of two semesters. The first semester utilized the traditional Learning Management System (LMS) threaded discussion board. The second semester incorporated Google Docs as the discussion platform. Overall, students using Google Docs made 68 percent more posts per student than students using the traditional LMS discussion board. Students using Google Docs also demonstrated more engagement by sharing professional experiences and teaching strategies more often than those students using the traditional LMS discussion board. While the data are encouraging, limitations of this study encourage additional research in the areas of discussion platform, discussion group size, and group assignment methods.
\end{abstract}

\section{KEYWORDS}

student engagement, online discussion, online learning environment, discussion board, student participation

\section{INTRODUCTION}

This study grew from efforts to find a more engaging way to conduct discussion activities in asynchronous online classes. The discussion activities examined in this study were graded assignments for a graduate course in school and classroom assessment. The majority of the students were Pre-K-12 teachers enrolled in the master of arts in teaching program at a regional university in the southeastern United States. The main goal of these discussion activities was to provide opportunities for students to apply the course content by discussing current topics and issues, such as assessment methods and standardized testing requirements, related to their practice as educators. A secondary goal was for these discussions to provide opportunities for students to build relationships that supported socially constructed learning.

The three areas often considered to be the foundation of best practice for promoting engaged student learning in online classes are: 1) student interaction with the instructor, 2) interaction and collaboration between students, and 3) authentic learning experiences (Garrison, Anderson, and Archer 2003). Online discussion board activities have traditionally been a primary method of providing student-to-student interaction in asynchronous online classes (Aloni and Harrington 2018). However, both faculty and students identify threaded discussion board platforms as a key weakness of Learning 
Management Systems (LMS) (Dahlstrom, Brooks, and Bichsel 2014). Gao, Zhang, and Franklin (2013) summarize the challenges of threaded discussion forums with the statement that "there is not much meaningful interaction taking place in threaded forums" (470). The format for traditional, online discussions using an LMS discussion board platform requires students to participate by posting a thread and/or by replying to another student's thread. To read other students' threads, each one must be clicked on individually. Often students make only the required number of posts for an assignment and do not explore the discussion further. I experienced a similar lack of student engagement with discussion activities after the first semester of teaching an assessment course in fall 2018 using the Desire2Learn Brightspace (D2L) discussion board.

The Productive Online Discussion Model proposed by Gao, Wang, and Sun (2009) outlines four aspects of effective discussion that reflect my online discussion goals. The Productive Online Discussion Model argues that an effective discussion requires students to (1) discuss to comprehend, (2) discuss to critique, (3) discuss to construct knowledge, and (4) discuss to share (471-72). As I read my class discussion posts on the D2L platform from fall 2018, I saw evidence of comprehension of the course content, but not of the other three aspects. Students were providing correct answers to the question prompts but going no further. Since the structure of the threaded discussion board requires students to make their posts and then view and comment on other students' posts, there was a lot of repetition of the same information. Most students only viewed and commented on two or three other posts and there was very little evidence of productive discussion. I realized that I was seeing examples of the limitations of the LMS discussion platform to student engagement.

I had used Google Docs for collaborative activities outside the classroom and wondered if it would work as a platform for online discussions in my asynchronous online classes. I decided to try using Google Docs as the discussion platform when I taught the course the next semester. The only change required in my course structure was to use the assignment tool in D2L to create my discussion activity assignments rather than the discussion tool. I included links to the Google Docs in the assignment instructions. Assignment instructions and discussion prompts were also posted on each Google Doc. After implementing the change to Google Docs for online discussion assignments, I noticed several key improvements. As an instructor, I found it much easier to review and grade discussions. I could check the version history for the Google Doc to see how often each student had participated in the discussion and I could quickly read through all posts in just one document. I also noticed an improvement in the quality of student discussion. After completing the second semester, I decided to conduct this study to compare the discussions from both semesters and assess the differences. Discussion activities continue to serve as a central activity in online courses (Aloni and Harrington 2018). Thus, finding more effective ways to structure the discussions can benefit both students and educators.

\section{BACKGROUND}

This study builds on research around socially constructed learning in asynchronous online learning environments. Learning through social interactions with others is at the heart of social cognitive theory. Bandura (1986) discussed an individual's response to social interactions as the way that one makes sense of their world and develops cognitions about their own self in relation to self-efficacy, selfregulation, and self-evaluation. Motivation is also important to our discussion of socially constructed learning. Schunk (2012) argues motivation is directly linked to learning, stating that "motivated students expend greater effort," and that "motivation engages students in activities that facilitate learning" (346). 
A student's sense of self-efficacy concerning their ability to learn increases their motivation to learn. Interacting with classmates in an engaging discussion activity helps students gain self-efficacy in their understanding and application of course content.

Educational psychology research also identifies teachers' confidence and feelings of self-efficacy as crucial to their success in how they teach and how their students learn (Poulou 2007). The theoretical framework of self-efficacy developed by Bandura (1977) provides the basis for these conceptions of teacher efficacy. Bandura related two types of expectancy to self-efficacy: (a) outcome expectancy, which is a measure of a person's belief that a given behavior will lead to a given outcome, and (b) efficacy expectancy, which is a measure of the conviction that one can successfully perform the behavior required to achieve the outcome. In summary, one's level of self-efficacy is dependent on the belief that doing a certain action will produce a given result and on the belief that one can do the action that is required to produce the result. Since my students are both students in this course and teachers or future teachers, providing the opportunity for them to build self-efficacy for both the course content and its application to their teaching is critical.

Participating in online discussions is often tied to extrinsic motivations, such as grades, but there are also important intrinsic motivators to consider. Lee and Martin (2017) found intrinsic motivation also included the desire to help classmates, have open interactions with other students, and form friendships. These findings are supported by the foundations of social cognitive learning. Vygotsky's (1978) work in developmental psychology and theory of mediated activity support the importance of interactions with others when making meaning of new knowledge. Creating online discussions that maximize intrinsic motivation to participate by increasing opportunities for social interaction should be a goal for any online discussion activity.

The online discussion activities that are the focus of this study not only provide the opportunity for social interaction, but also for the type of active learning that supports critical inquiry. Brown (2014) found the intentional use of active learning strategies, such as online discussion, supported the development of higher-level thinking in preservice teachers over the course of a semester. Levy (2008) found graduate students in an online learning program valued making and reading online discussion posts as important learning activities. Leflay and Groves (2013) documented the effectiveness of online discussion activities in a sports sociology course in supporting cognitive aspects of learning such as information processing, fact transmission, and interpretation of academic content. These findings are supported by numerous other researchers (Delahunty 2018; Ho and Swan 2007).

Evaluating the effectiveness of a learning activity to transfer knowledge requires looking at several levels of learning. Learning taxonomies, such as Bloom's Revised Taxonomy (Krathwohl 2002), and theories of learning approaches, such as deep learning as defined by Marton, Dall'Alba, and Beaty (1993), provide structures for studying learning activities. The concept of deep learning mirrors Bloom's Revised Taxonomy levels in that it leads the learner from approaching learning by memorizing to the application of knowledge and construction of new knowledge. Henri (1992) identified five key dimensions for analysis of online discussion. These were participation rate, interaction type, social cues, and cognitive skills, as well as depth of processing and metacognitive skills and knowledge. Hara, Bonk, and Angeli (2000) build on Henri's work with a study focused on how online discussions might encourage higher-order cognitive and metacognitive processing. They found online discussions allowed 
students time to reflect on course content and make more in-depth cognitive and social contributions to the discussion than might be possible in a traditional classroom setting.

One way to enhance the effectiveness of online discussion activities is to create small groups for discussion activities rather than having whole class discussions (Akcaoglu and Lee 2016). Akcaoglu and Lee's study compared students' experiences in both whole class discussions and small group discussions with four to five participants. They found students participating in small group online discussions perceived a higher level of social presence in terms of sociability, social space, and group cohesion. Baker (2011) found forming small groups for online discussions facilitated "student interaction and contributed to the group's construction of knowledge through dialogue about the course subject matter" (28).

Lin et al. (2016) compared the use of Google Docs with a traditional paper-and-pencil method for an activity in collaborative concept mapping in a physics class and found the use of Google Docs did not significantly affect physics achievement, but did enhance collaborative learning and physics concept representation. Students also reported a positive experience when using Google Docs for collaborative work in a translation class (Sudrajat and Purnawarman 2019). Positive student experiences with Google Docs have also been reported for collaborative writing projects that include online peer editing (Ebadi and Rahimi 2017) and feedback on writing assignments (Neumann and Kopcha 2019).

This study builds on the foundation of the literature related to the use of online discussions to provide opportunities for social interaction and to foster the type of active learning that supports critical inquiry. However, there is a gap in the literature related to the use of Google Docs as an alternate platform for online discussion activities. This study contributes to this literature by exploring student engagement with online discussion activities using Google Docs.

\section{PURPOSE}

The purpose of this study was to compare student participation in online discussion activities using two different online discussion platforms. In one semester the traditional LMS threaded discussion board was utilized. The next semester incorporated Google Docs as the discussion platform. Student participation was measured by the number of posts per student in each discussion and by the quality of student posts. For the purpose of this study, quality of student posts was assessed by students' willingness to engage by advancing the discussion with contributions beyond the prompt and by sharing professional experiences. The research questions that guided this study were:

1. Is there a difference in the number of student posts between the two platforms?

2. Is there a difference in the quality of student posts between the two platforms?

\section{METHOD}

This study was conducted at a regional, public university in the southeastern United States. The graduate course examined in the study serviced several fully online programs in the college of education. The majority of the student participants were in the master of arts in teaching (MAT) program focused on obtaining a master's degree and a teaching certificate. Most were concurrently employed as full-time Pre-K to grade 12 teachers while completing this course. Institutional Review Board (IRB) approval was received, and data was analyzed after grades were posted for the courses. Since the decision to conduct this study was not made until after the courses were completed and the data to be analyzed had already been collected, the IRB application was written to request permission only to use the existing data 
contained in the course discussion assignments and in the analytics from the learning management system. Permission was not obtained to use any data that might identify individual students and a commitment was made to present and discuss all data in aggregate.

This study examines discussion assignments from an asynchronous online course in school and classroom assessment that the author teaches most semesters. The course is taught over a 16-week semester with content and assignments posted each week for students to complete asynchronously. Data for this study were collected from the sections of the course that the researcher taught during the fall 2018 and spring 2019 semesters. This study examined three online discussions that were graded assignments for the course. Students had one week to complete each discussion assignment. Students earned points for posting on at least two different days during the week for each assignment and for making substantial contributions to the discussion. It was suggested that students make at least three posts and/or replies to each discussion, but this was not required. Feedback was provided as each assignment was graded to help students meet assignment expectations.

The research examined all three discussion assignments from both semesters. The discussion questions, instructions, and assignment requirements remained the same for both semesters. For the course taught during fall 2018, the LMS Desire2Learn Brightspace (D2L) threaded discussion board was used. For the course taught during spring 2019, Google Docs was used as the discussion platform. The discussion prompts focused on ethical decisions related to student assessment, effective grading methods, and the impacts of standardized testing on student learning. The instructions and prompts for each of the three discussion are included in the appendix.

During both semesters, students worked in small groups to complete the discussion assignments. While the discussion instructions remained the same for each semester, the groups were organized differently. This methodological difference may have some impact on the study's findings and is considered in the discussion of the results. Students in both semesters were divided into groups and worked with the same group for all three assignments. During fall 2018, the 49 students taking the course were randomly divided into four groups with 11 to 13 students per group. In spring 2019, the 60 students taking the course were divided into nine groups of five to eight students each. Students in this semester were assigned to groups based on grade level teaching interests (lower elementary, upper elementary, or high school). Seven of the nine groups included participants with similar grade level interests and two of the nine contained participants who did not state a grade level interest. This change in how groups were assigned was a pedagogical choice made before the decision to conduct this study. The decision was made after completion of the two courses, so the group size and assignment method could not be changed. Limited analysis of the effect of group size and assignment method on student participation in the discussion activities is presented with the results. The difference in group size and composition is noted as a limitation of this study and addressed further in the discussion of results.

Structurally, the discussions were defined by the platforms. The groups using the LMS discussion board platform in fall 2018 each had a separate discussion forum for postings and comments. Students only had access to their group's discussion forum. The groups using Google Docs in spring 2019 each had one Google Doc for the semester. Each student was assigned a color to use for their posts and comments to help identify contributions. The same Google Doc was used all semester with each new discussion, including instructions and prompts being added at the top of the page. This allowed students to have access to all of the discussions in one document and saved the instructor time when 
creating new discussion assignments. The instructor could also view the document version history to see when individual students posted. Google Docs were maintained in a class file folder on the instructor's university Google Drive.

The researcher collected and analyzed data from each discussion platform to address the two research questions. The first research question asked, "Is there a difference in the number of student posts between the two platforms?" To answer this, the number of posts per student was counted for each discussion. The counts for the students using the LMS platform were obtained from the topic statistics provided by the platform for each discussion topic. For the students using Google Docs, the number of posts for each student was counted using the students' color-coded comments and the version history.

The second research question asked, "Is there a difference in the quality of student posts between the two platforms?" For the purpose of this study, quality of student posts was assessed by students' willingness to engage by advancing the discussion with contributions beyond the prompt and by sharing professional experiences. To answer the question related to the quality of student posts, a qualitative analysis of the discussion posts and comments was conducted. An inductive coding method was used for the initial approach. I was looking to develop codes that would allow me to identify differences in the quality of the discussions. The discussion instructions, which were identical both semesters, encouraged students to share experiences, express concerns, and ask questions. Coded statements in posts and comments consistently fit into the following coding categories: course content, agreement/approval with prior comment, shared experience, teaching strategy, or question/request for information. Examples of each type of statement are included in table 1.

Table 1. Coding category examples

\begin{tabular}{|c|c|}
\hline Code & Example \\
\hline Course content & Answering the discussion questions using content from course materials \\
\hline $\begin{array}{l}\text { Agreement/approval } \\
\text { with prior comment }\end{array}$ & $\begin{array}{ll}\bullet & \text { I agree with ... } \\
\bullet & \text { I feel the same way... } \\
\bullet & \text { I also like... }\end{array}$ \\
\hline Shared experience & $\begin{array}{l}\text { Examples of experiences with aspects of the course content: } \\
\text { - } \quad \text { At my school we do... } \\
\text { - } \quad \text { I had a student... } \\
\text { - } \quad \text { We use ... }\end{array}$ \\
\hline Teaching strategy & $\begin{array}{l}\text { Provides examples of teaching strategies or resources related to the } \\
\text { course content }\end{array}$ \\
\hline Question & 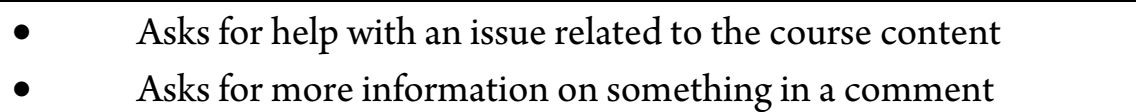 \\
\hline
\end{tabular}

This initial reading and coding aimed to define the types of post content to allow for meaningful comparison between the two platforms. I wanted to identify coded statements that could be used as a measure of a quality post. These were statements that contributed to the discussion in a meaningful way that was beyond just restating course content or agreeing with other students. In the next phase, I identified consistencies across the posts. For example, I realized comparing the statements coded 
"course content" was not meaningful because with the LMS platform, each student made their post that included the answer to the question using the course content and then made comments to other students' posts. Thus, there was considerable repetition of the same information. Both platforms had a significant number of comments that provided an agreement or a confirmation that were considered agreement/approval comments that did not add to the discussion in a significant way. There were only three items coded as "questions" in all the discussion groups on both platforms. What was interesting to compare were the differences between the platforms for statements coded as "shared experiences" and "teaching strategies." Statements in posts and comments attributed to these codes went beyond simply restating the course content and contributed to the conversation in meaningful ways. These statements were considered to be a measure of the quality of posts/comments. These statements contributed to the discussion at higher cognitive levels consistent with deep learning.

The topics for the three discussions studied were ethics, grading, and testing. Discussion posts were analyzed by group within each topic for the LMS and the Google Docs discussions. To support consistent and accurate coding, the reviewer alternated coding discussions between each platform. All groups for one discussion topic were coded before starting on the next topic.

Each discussion was analyzed through a systematic process of sentence by sentence coding of posts and comments, and then coded statements were counted by type. The two codes of shared experiences and teaching strategies were totaled and reported as "shared experiences and teaching strategies" and were considered to be a measure of quality for the associated posts and comments. The total number of shared experiences and teaching strategy statements for each discussion was divided by the number of students who participated in the discussion to obtain the average number of shared experiences and teaching strategy statements per student.

\section{RESULTS}

The results of this study are presented in two sections. Student participation in discussion activities was compared by two measures: the number of discussion posts written and the quality of the discussion posts as measured by the number of shared experiences and teaching strategy statements made by participating students.

\section{Participation in online discussion activities}

Participation in the discussions was measured by the number of posts per student. There was a significant difference in the number of posts made between the Google Docs platform and the LMS platform for each of the three discussions. For the ethics discussion, students using the LMS platform made an average of 4.14 posts per student, while those using the Google Docs platform made an average of 6.15 posts per student. The number of posts per student for the ethics discussion was 32.68 percent higher for those using the Google Docs platform than for those using the LMS platform. For the grading discussion, students using the LMS platform made an average of 2.49 posts per student while those using the Google Docs platform made an average of 4.61 posts per student. The number of posts per student for the grading discussion was 45.99 percent higher for those using the Google Docs platform than for those using the LMS platform. For the testing discussion, students using the LMS platform made an average of 2.07 posts per student while those using the Google Docs platform made an average of 3.44 
posts per student. The number of posts per student for the testing discussion was 39.83 percent higher for those using the Google Docs platform than for those using the LMS platform (figure 1).

\section{Figure 1. Number of posts per student:}

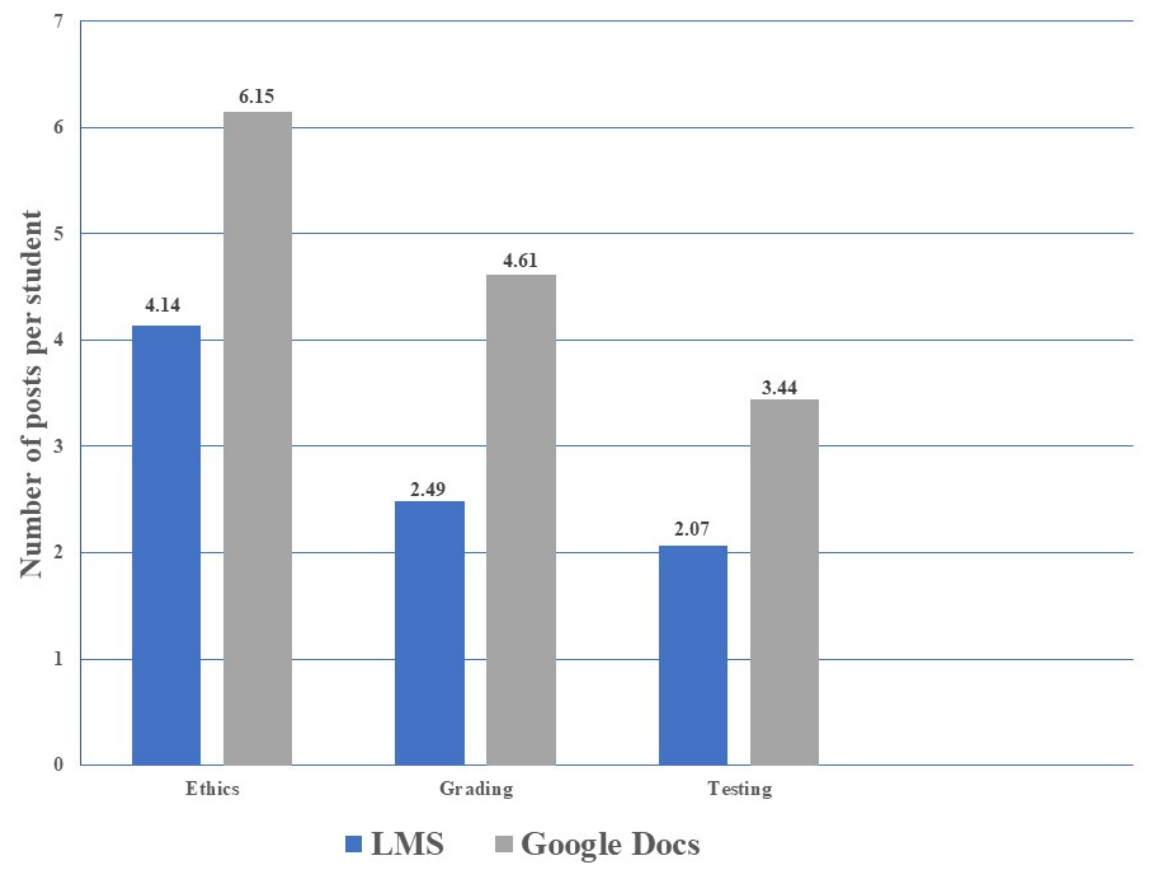

The difference in group size and composition is noted as a limitation of this study. To provide additional insights as to the possible effect of these differences, some additional analysis of individual group participation was conducted. To further compare the participation in the discussion activities between the two platforms, the average number of posts in all three discussions was calculated for each group. Since some students did not participate in all three of the discussions, the average number of participating students for all three discussions was calculated for each group. This was the number of students used to calculate the average number of posts per student (table 2).

Table 2. Total posts for all three discussions per group

\begin{tabular}{|c|c|c|c|}
\hline \multicolumn{4}{|c|}{ LMS platform } \\
\hline $\begin{array}{l}\text { Number of students } \\
\text { per group }\end{array}$ & $\begin{array}{l}\text { Number of } \\
\text { participating } \\
\text { students* }\end{array}$ & $\begin{array}{c}\text { Avg. number of total posts per } \\
\text { student }\end{array}$ & Overall avg. number of posts per student \\
\hline 11 & 8.66 & 7.52 & \multirow{4}{*}{8.62} \\
\hline 12 & 11.67 & 8.35 & \\
\hline 13 & 10 & 10.35 & \\
\hline 13 & 11.33 & 8.21 & \\
\hline \multicolumn{4}{|c|}{ Google Docs platform } \\
\hline $\begin{array}{c}\text { Grade level interest/ } \\
\text { number of students } \\
\text { per group }\end{array}$ & $\begin{array}{l}\text { Number of } \\
\text { participating } \\
\text { students* }\end{array}$ & $\begin{array}{c}\text { Avg. number of total posts per } \\
\text { student }\end{array}$ & Avg. number of total posts \\
\hline $\begin{array}{l}\text { Lower elem. } \\
\text { (LE) } / 7\end{array}$ & 6.67 & 16.94 & Overall $=14.45$ \\
\hline
\end{tabular}




\begin{tabular}{|c|c|c|c|}
\hline $\begin{array}{c}\text { Lower elem. } \\
(\mathrm{LE}) / 7\end{array}$ & 7 & 14.57 & \\
\hline $\begin{array}{c}\text { Lower elem. } \\
(\mathrm{LE}) / 7\end{array}$ & 7 & 11.43 & \\
\hline $\begin{array}{c}\text { Upper elem. } \\
(\text { UE }) / 5\end{array}$ & 5 & 10.60 & \\
\hline $\begin{array}{c}\text { Upper elem. } \\
\text { UE) } / 8\end{array}$ & 8 & 15.39 & \\
\hline High school/7 & 6.67 & 18.29 & \multirow{2}{*}{ Random groups $=14.24$} \\
\hline High school/6 & 6 & 11.83 & \\
\hline $\begin{array}{c}\text { Mixed } \\
\text { (random) } / 7\end{array}$ & 6.33 & 16.75 & \\
\hline $\begin{array}{c}\text { Mixed } \\
\text { (random) } / 6\end{array}$ & 6 & 11.60 & \\
\hline
\end{tabular}

Note: The number of participating students* was calculated by adding the number of students participating in each of the three discussions and dividing by three. The total number of posts was divided by the average number of participating students to calculate the average number of posts per student.

The number of students assigned to each group using the LMS platform ranged from 11 to 13, while the average number of participating students ranged from 8.66 to 11.67 . The overall average number of posts per student was 8.62. The average number of posts per group was lowest for the smallest group, which had 8.66 participating students who averaged 7.52 posts per student. The groups with the highest number of participating students, 11.33 and 11.67 , averaged 8.21 and 8.35 average posts per student. The group with 10 participating students had the highest average number of posts with 10.35 posts per student.

The overall average number of posts per student for the groups using Google Docs was 14.45. Students in the groups assigned by teaching interests averaged 14.50 posts per student. Students in groups assigned without information on teaching interests averaged 14.24 posts per student. The number of posts per group for all seven groups ranged from 10.60 to 18.29.

To further examine the variations between groups that may have been affected by group size and/or group assignment method, the total number of posts per discussion activity for each group is presented in figure 2. There appears to be a greater variation in the number of posts within the Google Doc groups than within the LMS platform groups. Four of the Google Docs groups made a consistently higher number of posts on the discussions than the other Google Doc groups, whereas there is not as much variation between the groups using the LMS platform. This is noted as a limitation of the study. 
Figure 2. Total posts for each discussion activity per group

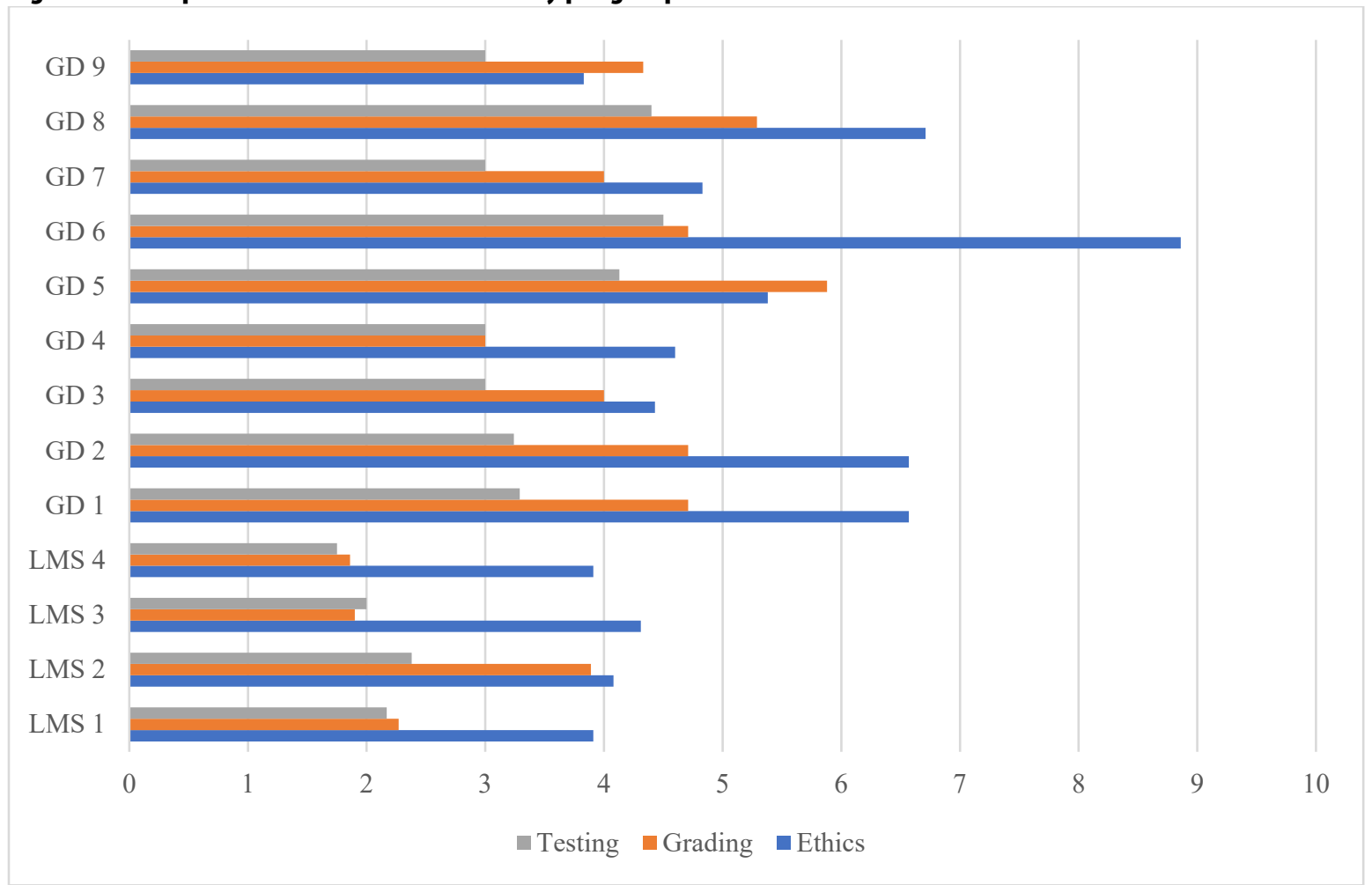

The total number of shared experiences and teaching strategies per discussion for each group is presented in figure 3. There appears to be more variation in responses within the groups using Google Docs than within the groups using the LMS discussion platform, which is noted as a limitation of this study. Further research will be needed to determine if group size, group assignment methods, or some other group dynamic has a significant effect on student engagement with discussion activities. 


\section{Figure 3. Total shared experiences and teaching strategies for each discussion activity per group}

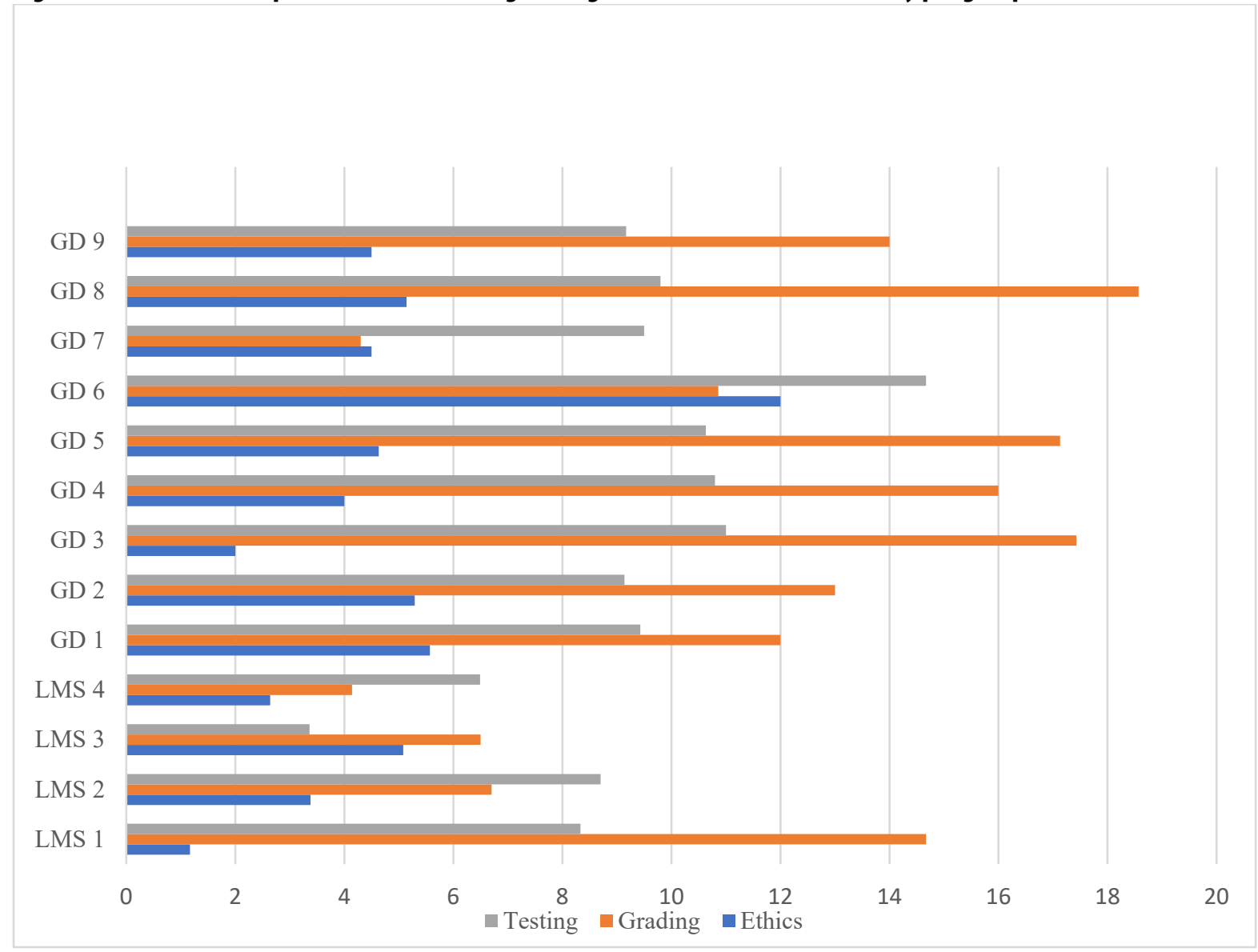

The total number of views of posts was extremely low for the LMS discussions compared to the total number of posts for all discussions. This indicated that students were contributing to the discussion as expected for the assignment, but they were not reading other posts and thus not gaining the benefits of the shared information. The average number of views per student ranged from a low of 1.75 posts viewed per student to a high of just 4.08 per student (figure 4 ). The total posts in each group available for the student to view ranged from a low of 13 posts in one group to a high of 56 posts in another.

In contrast, the entire Google Doc discussion is in one document and students do not have to open individual posts to view them. The posts and replies on the Google Doc platform read like an ongoing conversation giving the impression that students were reading the entire document and contributing appropriately, although I was not able to document that with this study. 
Figure 4. LMS discussion board total posts vs. average individual student views of posts

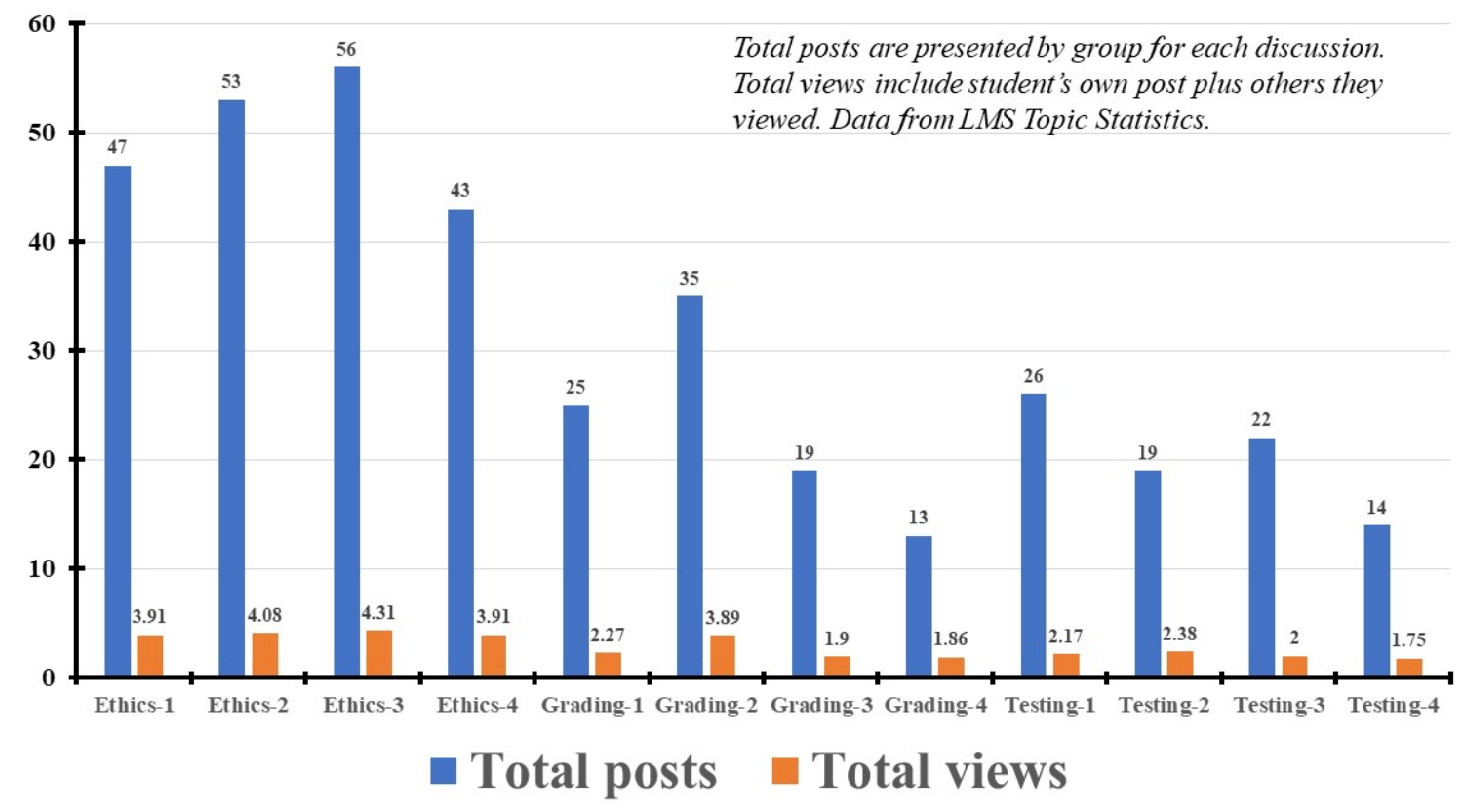

\section{Quality of posts in online discussion activities}

Research question two focused on differences in the quality of posts between the two platforms. In the analysis of the data, statements coded as shared experiences and teaching strategies were considered examples of discussion contributions that went beyond restating the course content to contribute to the conversation in more meaningful ways. Sentence by sentence coding was performed, so an individual post or comment may have included more than one statement coded as "shared experience" or "teaching strategy."

For the ethics discussion, students using the LMS platform shared an average of 3.14 statements coded as shared experiences or teaching strategies, while students using Google Docs shared 5.35 per student. For the grading discussion, students using the LMS platform shared an average of 6.66 statements coded as shared experiences or teaching strategies while students using Google Docs shared 13.86 per student. For the testing discussion, students using the LMS platform shared an average of 6.49 statements coded as shared experiences or teaching strategies while students using Google Docs shared 10.44 per student (figure 5).

Students went beyond answering discussion questions and offered shared experiences and teaching strategies more often when using Google Docs. For the ethics discussion, students shared experiences and teaching strategies 41.31 percent more often than students using the LMS platform. For the grading discussion, students shared experiences and teaching strategies 51.95 percent more often than students using the LMS platform. For the testing discussion, students shared experiences and teaching strategies 38.70 percent more often than students using the LMS platform. 


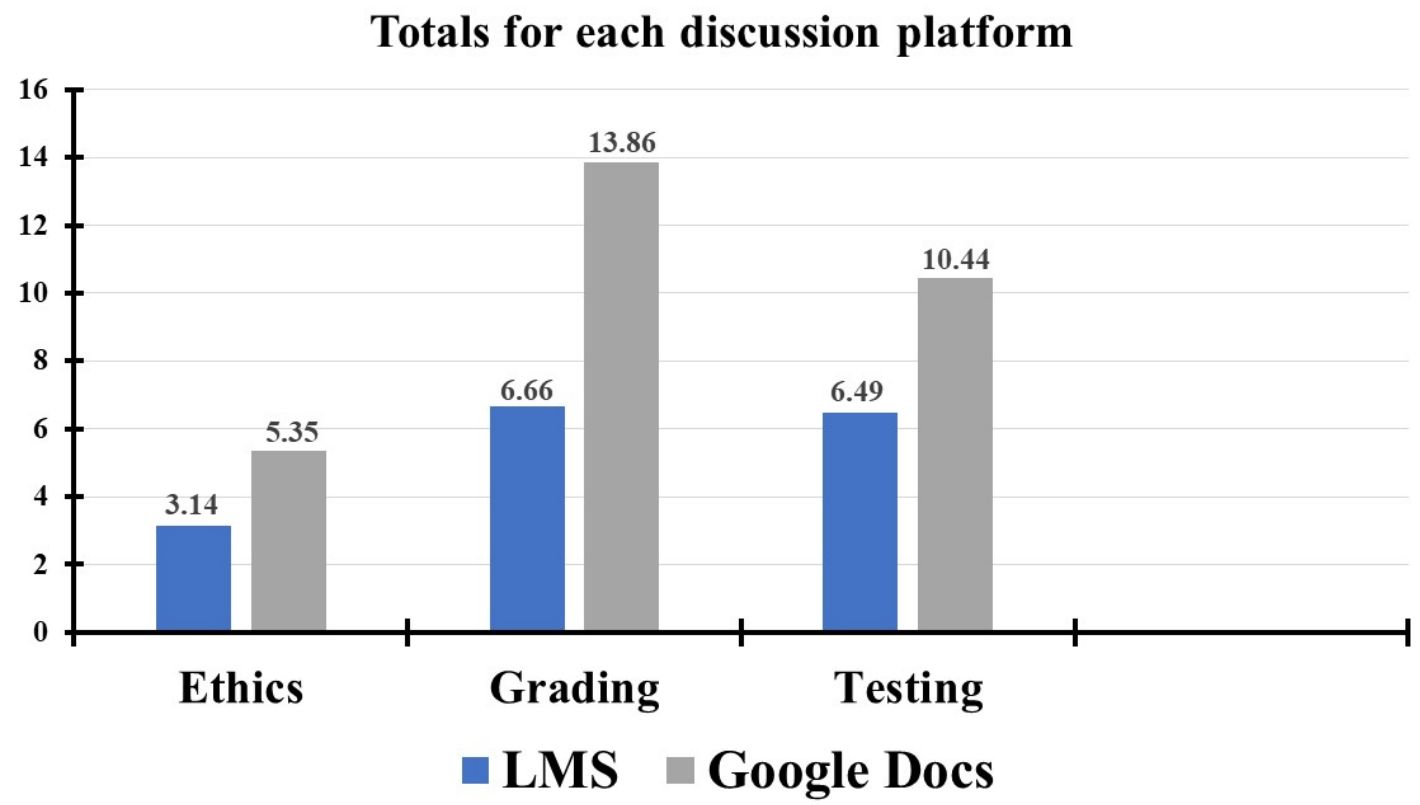

\section{DISCUSSION}

The purpose of this study was to compare student participation in online discussion activities when using two different online discussion platforms. Student participation was measured by the number of posts per student in each discussion, as well as the quality of student posts, which was measured by the number of shared experiences and teaching strategies included. The results of this study support the use of Google Docs as an alternative to the threaded discussion format used by many LMS platforms. While students using Google Docs engaged with class discussions through a higher numbers of posts and a higher number of shared experiences and teaching strategies than those using the LMS discussion platform, there were some limitations to this study that must be considered when interpreting these results. Some additional areas of interest for further research were also raised.

Students using Google Docs made 68 percent more posts than students using the LMS platform. Students using Google Docs contributed more quality statements than those using the LMS platform. For the ethics discussion, students shared experiences and teaching strategies 41.31 percent more often than students using the LMS platform. For the grading discussion, students shared experiences and teaching strategies 51.95 percent more often than students using the LMS platform. For the testing discussion, students shared experiences and teaching strategies 38.7 percent more often than students using the LMS. The Productive Online Discussion Model (Gao, Wang, and Sun 2009) asserts that for an effective discussion, students must actively (1) discuss to comprehend, (2) discuss to critique, (3) discuss to construct knowledge, and (4) discuss to share. This study demonstrated the potential for Google Docs to engage students in discussing "to share." While these findings seem quite significant, it is important to temper them with the unknown effect that the differences in how the discussion groups were formed might have had on student participation with the discussions.

While no conclusions as to the effect of group size or composition can be made from this data, 
some observations can be shared. As shown in figures 2 and 3, there were greater variations in both the number of posts and the number of shared experiences and teaching strategies between the Google Docs groups and the LMS groups. As I read through the Google Docs discussion, I noted several groups that consistently engaged in posting to the discussion and sharing experiences. It is also possible that group size and composition may have shaped the tone and content of the conversation. For example, a student who teaches first grade may be more likely to share experiences with a group of early elementary teachers than in a group that includes high school teachers. In several groups there were individual students who consistently made strong posts that seemed to stimulate others to respond. I did not see this to the same degree in the groups using the LMS platform. This may be attributed to students most often only viewing the few posts to which they responded. Further research is needed to corroborate the results of this study and to quantify the impact of variables such as group size, group assignment methods, and the impact of individual students on engagement with the discussion.

Some of the constraints of using the LMS discussion board platform that have been noted elsewhere (Dahlstrom, Brooks, and Bichsel 2014; Gao, Zhang, and Franklin 2013) were also seen in this study. Specific concerns include students only contributing the minimum required number of posts and contributing posts that do not add to the discussion such as agreement/approval type comments. It was also noted that students using the LMS platform were reading only a small percentage of the total posts by their group members, thus missing out on important learning opportunities from classmate posts. The Google Docs format seems to encourage students to read through the other posts in order to add to the conversation, but further research is needed to determine if this, in fact, happens.

Some additional benefits were also realized during the discussion analysis. As an instructor, I found the Google Doc discussions more interesting to read because there was less duplication in responses, and it was easier to follow the thread of the discussion. Google Doc discussions read like conversations. Students provided examples of how they used aspects of the course content in their classrooms and shared related teaching tips and resources.

This study compares the experience of using an LMS threaded discussion to the experience of using Google Docs as a discussion platform with students who were actively engaged working in the profession related to the course. This provided the added benefit of allowing students to share applications of course content and to learn teaching strategies related to the course content from each other. This benefit might be important in other disciplines where students are also practicing professionals. The structural difference of being able to view all group posts in one place when using Google Docs rather than through threads that must be viewed one at a time would be transferable to any discipline. The findings of this study support the use of Google Docs to improve student engagement with asynchronous online discussions.

Mary L. Morse is an assistant professor of educational research at the University of West Georgia (USA).

\section{REFERENCES}

Akcaoglu, Mete, and Eunbae Lee. 2016. "Increasing Social Presence in Online Learning through Small Group Discussions." International Review of Research in Open and Distributed Learning 17, no. 3: 1-17.

Aloni, Maya, and Christine Harrington. 2018. "Research Based Practices for Improving the Effectiveness of Asynchronous Online Discussion Boards." Scholarship of Teaching \& Learning in Psychology 4, no. 4: 27181. https://doi.org/10.1037/stl0000121. 
Baker, David. 2010. "Improving Pedagogy for Online Discussions." Business Education Innovation Journal 3, no. 2 December 2011:26-29.

Bandura, Albert. 1977. "Self-Efficacy: Toward a Unifying Theory of Behavioral Change." Psychological Review 84, no. 2: 191-215. https://doi.org/10.1037/0033-295X.84.2.191.

Bandura, Albert. 1986. Social Foundations of Thought and Action: A Social Cognitive Theory. Englewood Cliffs, NJ: Prentice Hall.

Brown, Amber. 2014. "Implementing Active Learning in an Online Teacher Education Course." American Journal of Distance Education 28: 3, 170-82.

Dahlstrom, Eden, D. Christopher Brooks, and Jacqueline Bichsel. 2014. “The Current Ecosystem of Learning Management Systems in Higher Education: Student, Faculty, and IT Perspectives." Research report. Louisville, CO: ECAR, September 2014. Available from http://www.educause.edu/ecar.

Delahunty, Janine. 2018. "Connecting to Learn, Learning to Connect: Thinking Together in Asynchronous Forum Discussion." Linguistics and Education 46, 12-22. https://doi.org/10.1016/j.lingted.2018.05.003.

Ebadi, Saman, and Masoud Rahimi. 2017. "Exploring the Impact of Online Peer-Editing Using Google Docs on EFL Learners' Academic Writing Skills: A Mixed Methods Study." Computer Assisted Language Learning 30, no. 8: 787-815. https://doi.org/10.1080/09588221.2017.1363056.

Gao, Fei, Charles Xiaoxue Wang, and Yanling Sun. 2009. "A New Model of Productive Online Discussion and its Implication for Research and Discussion." The Journal of Educational Technology Development and Exchange, 2, 1, 65-78.

Gao, Fei, Tianyi Zhang, and Teresa Franklin. 2013. "Designing Asynchronous Online Discussion Environments: Recent Progress and Possible Future Directions." British Journal of Educational Technology 44, no. 3:, 46983.

Garrison, D. Randy, Terry Anderson, and Walter Archer. 2003. "A Theory of Critical Inquiry in Online Distance Education." In M.G. Moore and W. G. Anderson (Eds.), Handbook of Distance Education, 113-27. Mahwah, $\mathrm{NJ}$ : Erlbaum.

Green, Susan, and Robert Johnson. 2010. Assessment is Essential. New York; McGraw-Hill.

Hara, Noriko, Curtis Bonk, and Charoula Angeli. 2000. "Content Analysis of Online Discussion in an Applied Educational Psychology Course." Instructional Science 28, no. 2:, 115-52.

Henri, France. 1992. "Computer Conferencing and Content Analysis." In: Kaye A.R. (eds) Collaborative Learning Through Computer Conferencing. NATO ASI Series (Series F: Computer and Systems Sciences), vol. 90. Springer, Berlin, Heidelberg. https://doi.org/10.1007/978-3-642-77684-7.

Ho, Chia-Huan, and Karen Swan. 2007. "Evaluating Online Conversation in an Asynchronous Learning Environment: An Application of Grice's Cooperative Principle." The Internet and Higher Education 10, no. 1:3-14. https://doi.org/10.1016/j.iheduc.2006.11.002.

Krathwohl, David. 2002. "A Revision of Bloom's Taxonomy: An Overview." Theory into Practice 41, no. 4:212-18.

Lee, Joohi, and Lesisa Martin. 2017. "Investigating Students' Perceptions of Motivating Factors of Online Class Discussions." The International Review of Research in Open and Distributed Learning 18, no. 5.

Leflay, Kathryn, and Mark Groves. 2013. “Using Online Forums for Encouraging Higher Order Thinking and 'Deep' Learning in an Undergraduate Sports Sociology Module." Journal of Hospitality, Leisure, Sport and Tourism Education, 13, 226-32. https://doi.org/10.1016/j.jhlste.2012.06.001.

Levy, Yair. 2008. "An Empirical Development of Critical Value Factors (CVF) of Online Learning Activities: An Application of Activity Theory and Cognitive Value Theory." Computers and Education 51, no. 4: 1664-75.

Lin, Yu-Tzu, Chia-Hu Chang, Huei-Tse Hou, and Ke-Chou Wu. 2016. "Exploring the Effects of Employing Google Docs in Collaborative Concept Mapping on Achievement, Concept Representation, and Attitudes." Interactive Learning Environments 24, no. 7: 1552-73. https://doi.org/10.1080/10494820.2015.1041398.

Marton, Ference, Gloria Dall'Alba, and Elizabeth Beaty. 1993. "Conceptions of Learning." International Journal of Educational Research, 19, 227-300.

Neumann, Kalianne, and Theodore Kopcha. 2019. “Using Google Docs for Peer-Then-Teacher Review on Middle School Students' Writing." Computers and Composition, 54. https://doi.org/10.1016/j.compcom.2019.102524.

Poulou, Maria. 2007. "Personal Teaching Efficacy and its Sources: Student Teachers' Perceptions." Educational Psychology 27, no. 9: 191-218. 
Schunk, Dale H. 2012. Learning Theories: An Educational Perspective. (6 ${ }^{\text {th }}$ Ed.) Boston: Pearson.

Sudrajat, Winny Nur Ardy, and Pupung Purnawarman. 2019. "Students' Perceptions on the Use of Google Docs as an Online Collaborative Tool in Translation Class." Lingua Cultura 13, no. 3: 209-16.

Vygotsky, Lev. 1978. Mind in Society: The Development of Higher Psychological Processes. Cambridge, MA: Harvard University Press. 
APPENDIX

Instructions and prompts for online discussions

\section{ETHICS DISCUSSION}

\section{Instructions for this discussion}

The following three scenarios are presented in table 1.7 on page 27 in your textbook (Green and Johnson 2010). The table lists data for perceptions as to whether these scenarios are ethical or unethical. Using what you have learned from chapter 1, please post your thoughts on the following three scenarios. Feel free to share experiences, express concerns, and ask questions - this is an informal group discussion, not a right/wrong assessment. Please check in frequently during the week and participate actively in the discussion.

\section{For each of the three scenarios, please discuss:}

1. Whether or not you think the scenario is ethical or unethical and why.

2. Using what you learned in chapter 1, suggest how the assessment might be changed to better serve student learning.

Scenario 1: A teacher always knows the identity of the student whose essay test she is grading.

Scenario 2: To enhance self-esteem, an elementary teacher addresses only students' strengths when writing narrative report cards.

Scenario 3: As a teacher finalizes grades, she changes one student's course grade from a B+ to an A because tests and papers showed the student had mastered the course objectives even though he had not completed some of his homework assignments.

\section{GRADING DISCUSSION}

I want you to feel free to share your original thoughts and not feel pressured by what others think. So, you will be graded on your active and thoughtful participation in this discussion, not on the specific content of your posts (I will view the history settings on the document to see everyone's contributions). Feel free to share experiences, express concerns, and ask questions - this is an informal group discussion, not a right/wrong assessment. Please check in frequently during the week and participate actively in the discussion.

Here are a few topics and questions to get us started. Try to check this document several times during the week and join in the discussion. I know you all have a lot of teaching experience and it would be great to share and learn from each other. Feel free to respond to any of these prompts or add new questions and/or topics.

\section{Grading challenges}

What challenges are hardest for you when it comes to grading? 


\section{Grading systems}

What grading systems do you use - letter grades, standards-based, not yet ... and why?

\section{Communicating with parents}

Tips and challenges for parent-teacher conferences?

\section{Parental involvement throughout the year}

Parental involvement in a child's education is one of the few things that has been proven to positively affect academic achievement. Sometimes at the school level, parental involvement focuses mainly on non-academic things such as fundraising or school projects like working on the school flower beds. I would love to hear what kinds of things you do or envision doing in your classroom to encourage parents to be involved with their child's academic achievement.

\section{Other topics related to grading and/or parental involvement TESTING DISCUSSION}

This will be our final discussion for this course. I know you all have a lot of teaching experience and it would be great to share and learn from each other. Feel free to respond to any of these prompts or add new questions and/or topics related to standardized tests.

How do you feel the use of NCLB related achievement tests has affected classroom instruction?

How do you prepare your students for standardized tests?

What challenges do you face explaining test results to parents?

Did you learn anything new from the video or articles on data-driven decisions that might help you in the classroom?

\section{(ब) $(1) \Theta$} have agreed that and the only role for copyright in this domain, should be to give authors control over the integrity of their work and the right to be properly acknowledged and cited, and to cite Teaching \& Learning Inquiry as the original place of publication. Readers are free to share these materials - as long as appropriate credit is given, a link to the license is provided, and any changes are indicated. 